\title{
Follow-up of women with breast cancer: comparison between MRI and FDG PET
}

\author{
Goerres, G W ; Michel, S C A ; Fehr, M K ; Kaim, A H ; Steinert, H C ; Seifert, Burkhardt ; von \\ Schulthess, G K ; Kubik-Huch, R A
}

\begin{abstract}
The aim of this study was to compare MRI of the breast with (18)F-fluoro-deoxy-glucose (FDG) positron emission tomography (PET) in patients with suspected local or regional breast cancer recurrence or suspected contralateral breast cancer. Thirty-two patients (mean age 57.2 years, age range $32-76$ years $)$ with suspected loco-regional recurrence $(n=19)$, chest wall recurrence $(n=5)$, and suspected secondary tumor of the contralateral breast $(n=8)$ underwent MRI of the breast and FDG PET of the whole body and breast region. Cytology/histology $(n=17)$ or a clinical follow-up examination $(n=15)$ with additional imaging served as the standard of reference. A McNemar test was performed to compare PET and MRI, and kappa was determined to quantify agreement of both methods. Sensitivity was 79 and $100 \%$, specificity was 94 and $72 \%$, and accuracy was 88 and $84 \%$ for MRI and PET, respectively. Additional metastases outside the field of view of MRI were found in PET in 5 patients. In this study both imaging methods had comparable accuracy. The detection of distant metastases with whole-body PET imaging can influence patient management.
\end{abstract}

DOI: https://doi.org/10.1007/s00330-002-1720-8

Posted at the Zurich Open Repository and Archive, University of Zurich

ZORA URL: https://doi.org/10.5167/uzh-19447

Journal Article

Published Version

Originally published at:

Goerres, G W; Michel, S C A; Fehr, M K; Kaim, A H; Steinert, H C; Seifert, Burkhardt; von Schulthess, G K; Kubik-Huch, R A (2003). Follow-up of women with breast cancer: comparison between MRI and FDG PET. European Radiology, 13(7):1635-1644.

DOI: https://doi.org/10.1007/s00330-002-1720-8 


\author{
Gerhard W. Goerres \\ Sven C. A. Michel \\ Mathias K. Fehr \\ Achim H. Kaim \\ Hans C. Steinert \\ Burkhardt Seifert \\ Gustav K. von Schulthess \\ Rahel A. Kubik-Huch
}

\section{Follow-up of women with breast cancer: comparison between MRI and FDG PET}

Received: 13 May 2002

Revised: 20 August 2002

Accepted: 13 September 2002

Published online: 13 November 2002

(C) Springer-Verlag 2002

G.W. Goerres $(\bullet) \cdot$ A.H. Kaim

H.C. Steinert - G.K. von Schulthess

Division of Nuclear Medicine,

University Hospital, Raemistrasse 100,

8091 Zurich, Switzerland

e-mail: gerhard.goerres@dmr.usz.ch

Tel.: +41-1-2552850

Fax: +41-1-2554414

S.C.A. Michel · R.A. Kubik-Huch Institute of Diagnostic Radiology, Department of Medical Radiology, University Hospital Zurich,

Raemistrasse 100, 8091 Zurich,

Switzerland

M.K. Fehr

Department of Gynaecology and Obstetrics, University Hospital Zurich,

Raemistrasse 100, 8091 Zurich,

Switzerland

B. Seifert

Department of Biostatistics,

University of Zurich, Raemistrasse 100,

8091 Zurich, Switzerland

\begin{abstract}
The aim of this study was to compare MRI of the breast with ${ }^{18}$ F-fluoro-deoxy-glucose (FDG) positron emission tomography (PET) in patients with suspected local or regional breast cancer recurrence or suspected contralateral breast cancer. Thirty-two patients (mean age 57.2 years, age range $32-76$ years) with suspected loco-regional recurrence $(n=19)$, chest wall recurrence $(n=5)$, and suspected secondary tumor of the contralateral breast $(n=8)$ underwent MRI of the breast and FDG PET of the whole body and breast region. Cytology/histology $(n=17)$ or a clinical follow-up examination $(n=15)$ with additional imaging served as the standard of reference. A McNemar test was performed to compare PET and MRI, and kappa was determined to quantify agreement of both methods. Sensitivity was 79 and $100 \%$, specificity was 94 and $72 \%$, and accuracy was 88 and $84 \%$ for MRI and PET,
\end{abstract}

respectively. Additional metastases outside the field of view of MRI were found in PET in 5 patients. In this study both imaging methods had comparable accuracy. The detection of distant metastases with wholebody PET imaging can influence patient management.

Keywords PET $\cdot$ MRI $\cdot$ Breast cancer $\cdot$ Chest wall $\cdot$ Recurrence

\section{Introduction}

Imaging is an important part in the management of breast cancer patients and is used for the detection and staging of a primary tumor as well as the evaluation of patients with suspected recurrence. Positron emission tomography (PET) with ${ }^{18}$ F-fluoro-deoxy-glucose (FDG) can help to visualize a primary lesion in the breast and can differentiate benign from malignant breast pathologies [1]. Furthermore, multifocality of lesions can be detected and PET has been proven accurate in identifying regional lymph node involvement of the axillary, supraclavicular, and internal mammary lymph nodes $[2,3]$. The PET provides a whole-body staging and can detect involvement of mediastinal lymph nodes and distant metastases [3, 4].

According to the recommendations of the European Society for Medical Oncology (http://www.esmo.org/ ESMO minimum clinical recommendations for diagnosis, adjuvant treatment and follow-up of primary breast cancer), patients with breast cancer should be examined clinically every 3-6 months for 3 years, every 6-12 months 
for 2 years, and then annually. In addition, breast cancer patients should undergo ipsilateral (after breast-conserving surgery) and contralateral mammography every 1-2 years to check for local recurrence or a second contralateral cancer. Additional imaging methods, such as chest X-ray, CT scans of the chest or abdomen, and bone scans, are not routinely recommended for asymptomatic patients. Accordingly, FDG PET is not recommended for routine follow-up studies, but it has been shown that FDG PET is useful for whole-body restaging in patients with suspected recurrence [5]. If recurrent disease is suspected on the basis of clinical or mammographic findings, ultrasound with fine-needle aspiration (FNA) or stereotactic biopsy under mammographic guidance is performed as the next step. Evaluation of patients with post-treatment changes due to surgery and radiation therapy is sometimes difficult. Post-treatment follow-up is a challenge in women after breast-conserving therapy, because tissue changes can mimic or obscure recurrent disease. Magnetic resonance imaging of the breast can be used as a problem-solving tool in the evaluation of these patients in whom equivocal changes are identified at mammography or physical examination [6]. Contrast-enhanced MRI has shown to be highly effective in identifying recurrent tumor, but false-positive cases, mostly due to post-therapeutic or inflammatory changes, may occur $[7,8,9,10$, $11,12,13]$. In a recent study a direct comparison between MRI and FDG PET was performed in women with suspicious breast lesions [3]. Both methods had the drawback of false-positive results, but PET was able to detect occult lymph node involvement and distant metastases not found with conventional staging methods such as skeletal scintigraphy, chest X-ray, and liver ultrasound [3].

The aim of this study was to compare FDG PET and MRI in the follow-up of patients with breast cancer.

\section{Materials and methods}

Patients

Between May 2000 and May 2001, 49 women were included prospectively and examined with FDG PET. All patients had a history of breast cancer and were scheduled for MR imaging due to suspected recurrent disease or a suspected second tumor in the contralateral breast. The study had been approved by the Institutional Review Board and written informed consent was obtained in all cases.

Thirty-two of 49 patients were available for comparison with MRI (age range $32-76$ years, mean age $57.2 \pm 10.2$ years). Of the other 17 patients, 3 patients were lost to follow-up and in 9 patients a standard of reference could not be obtained. In the remaining 5 patients, MRI was not available for comparison with PET, because it was non-diagnostic due to severe motion artifacts $(n=1)$, incomplete due to claustrophobia $(n=1)$, or the interval between the MRI and PET exceeded the time interval of 4 weeks, which had been defined as being still acceptable for our study $(n=3)$.

All patients included in the comparative study had been previously treated for breast cancer with surgery $(100 \%)$, radiation ther- apy $(44 \%)$, and chemotherapy (38\%; Table 1). Mastectomy was performed in 11 patients (bilaterally in patients 7 and 23 and unilaterally in patients $4,6,13,15,20,21,22,24,32)$. Initial diagnosis and treatment of breast cancer was made 8-260 months prior to PET and MR scans (median 32.5 months, mean 51.9 months; Table 1). Nineteen of 32 women $(60 \%)$ had equivocal clinical or mammographic findings of the ipsilateral side and thus suspected loco-regional recurrence could not be excluded (mean 58.6 years; Table 1). Five of 32 patients (16\%) had suspected chest wall recurrence ipsilateral to the initial disease (mean 58.6 years; Table 1). Eight of $32(25 \%)$ women had suspicious findings in the contralateral breast (mean 53.0 years; Table 1). In 22 women a lesion in the breast, thoracic soft tissues, or regional lymph node stations was palpable. In 4 women no lesion was palpable (patients 4, 11, 17, 21 ) and in 6 patients this information was not available (patients 5 , $12,19,28,30,31)$. Lesion size was $\geq 10 \mathrm{~mm}$ in 27 patients and $<10 \mathrm{~mm}$ in 4 (patients $4,5,6,17$ ). Lesion size was not documented in patient 31 .

\section{Standard of reference}

Cytology or histology was used as a standard of reference. If not available, patients with negative findings in MRI and/or negative PET findings underwent a follow-up examination after at least 12 months using additional imaging such as mammography with/without ultrasound and clinical evaluation (Table 2). In patients with suspected local or regional pathology, but without histological or cytological proof, further imaging methods were used to verify suspected loco-regional disease and distant metastases (Table 2). For the evaluation of local thoracic wall invasion CT scanning and/or bone scintigraphy was added. All available imaging studies, including mammography, ultrasound, CT, MRI, and PET, were read in consensus and the results were discussed with the gynecologist who had clinically examined the patient. This served to establish the reference standard for loco-regional disease and served for the decision to start a treatment.

Data acquisition

The PET scanning was done as follows: all patients fasted for at least $4 \mathrm{~h}$ prior to the PET scan. Approximately $45 \mathrm{~min}$ before image acquisition, the patients received an intravenous injection of $386 \mathrm{MBq}( \pm 83 \mathrm{MBq})$ FDG. Images were acquired on a GE Advance PET scanner (GE Medical Systems, Waukesha, Wis.) in 2D mode with an axial field of view (FOV) of $14.6 \mathrm{~cm}$. Emission scans were acquired with 4 min per FOV and overlap of one slice $(4.25 \mathrm{~mm})$ at the borders. Women scanned for suspected locoregional recurrence and contralateral breast cancer were placed in the PET scanner in a prone position and a PET scan localized on the breast fields using two axial FOV were acquired. For patient positioning we used an MRI breast coil support from which the actual receiver coil had been removed. This permitted to come as close as possible to the MR imaging position. Attenuation correction was obtained for these two FOV using the built-in ${ }^{68} \mathrm{Ge}$ sources of the scanner. After this PET acquisition, patients were placed supinely, and a scan from the pelvic floor to the head was performed. This whole-body scan was acquired to evaluate the patient with regard to distant metastases and was obtained without attenuation correction to save time. In the 5 women (patients 20-24; Table 2) who had had surgical ablation of one or both breasts, and who had a suspected recurrence in the thoracic wall, both studies, PET and MRI, were performed in supine position only. In these patients, PET scans without attenuation correction covering the whole body from the head to the pelvic floor were acquired.

An MRI scan of the breast was obtained in prone position on a 1.5-T scanner (Signa CV/I or Horizon, GE Medical Systems, 
Table 1 Patient characteristics

The three patient subpopulations, i.e., women with suspected ipsilateral recurrence, women with suspected thoracic wall recurrence, and women with suspected contralateral breast cancer, are listed together. In all patients receiving chemotherapy, the treatment was stopped several months before this study. Three patients underwent radiation treatment less than 18 months before the MRI and PET scans were acquired. This could disturb interpretation of lesions in an MRI scan, but was not a problem in the patients of this study

\begin{tabular}{|c|c|c|c|c|c|}
\hline $\begin{array}{l}\text { Patient } \\
\text { no. }\end{array}$ & $\begin{array}{l}\text { Indication for } \\
\text { PET and MRI }\end{array}$ & $\begin{array}{l}\text { Time since } \\
\text { first treatment } \\
\text { (months) }\end{array}$ & $\begin{array}{l}\text { Previous } \\
\text { chemotherapy }\end{array}$ & $\begin{array}{l}\text { Previous } \\
\text { radiotherapy }\end{array}$ & $\begin{array}{l}\text { Radiation } \\
\text { treatment stopped } \\
\text { (months ago) }\end{array}$ \\
\hline 1 & Local recurrence & 13 & No & Yes & 11 \\
\hline 2 & Local recurrence & 45 & No & Yes & $>18$ \\
\hline 3 & Local recurrence & 17 & Yes & No & \\
\hline 4 & Local recurrence & 232 & No & No & \\
\hline 5 & Local recurrence & 8 & Yes & No & \\
\hline 6 & Local recurrence & 149 & No & No & \\
\hline 7 & Local recurrence & 33 & No & No & \\
\hline 8 & Local recurrence & 12 & No & Yes & 10 \\
\hline 9 & Local recurrence & 44 & No & Yes & $>18$ \\
\hline 10 & Local recurrence & 14 & No & No & \\
\hline 11 & Local recurrence & 30 & Yes & Yes & $>18$ \\
\hline 12 & Local recurrence & 23 & No & Yes & $>18$ \\
\hline 13 & Local recurrence & 64 & No & No & \\
\hline 14 & Local recurrence & 18 & No & No & \\
\hline 15 & Local recurrence & 42 & Yes & Yes & 12 \\
\hline 16 & Local recurrence & 23 & No & Yes & $>18$ \\
\hline 17 & Local recurrence & 19 & No & No & \\
\hline 18 & Local recurrence & 45 & No & No & \\
\hline 19 & Local recurrence & 33 & Yes & Yes & $>18$ \\
\hline 20 & Thoracic wall & 260 & Yes & Yes & $>18$ \\
\hline 21 & Thoracic wall & 70 & No & Yes & $>18$ \\
\hline 22 & Thoracic wall & 22 & Yes & Yes & $>18$ \\
\hline 23 & Thoracic wall & 47 & No & No & \\
\hline 24 & Thoracic wall & 32 & Yes & No & \\
\hline 25 & Contralateral & 70 & Yes & No & \\
\hline 26 & Contralateral & 20 & Yes & No & \\
\hline 27 & Contralateral & 16 & No & No & \\
\hline 28 & Contralateral & 73 & No & No & \\
\hline 29 & Contralateral & 30 & Yes & Yes & $>18$ \\
\hline 30 & Contralateral & 69 & No & No & \\
\hline 31 & Contralateral & 19 & Yes & Yes & $>18$ \\
\hline 32 & Contralateral & 70 & No & No & \\
\hline
\end{tabular}

Milwaukee, Wis.) using a bilateral breast surface coil. A T1weighted 3D FSPGR sequence with the following parameters was used for image acquisition: TR $7.7 \mathrm{~ms}$; TE $1.8 \mathrm{~ms}$; flip angle $30^{\circ}$; matrix $252 \times 192$; field of view (FOV) $30 \times 30 \mathrm{~cm}$; slice thickness $3 \mathrm{~mm}$ without gap; and the frequency-encoding direction was anteroposterior. After a localizer scan, precontrast and four dynamic post-contrast $(0.1 \mathrm{mmol} / \mathrm{kg}$ body weight; Gd-DTPA, Magnevist, Schering, Berlin, Germany) image series $(0.5,1,3,8 \mathrm{~min})$ were obtained. The short echo time was chosen to save imaging time. The use of this imaging protocol has the possible drawback of opposed-phase effects leading to a reduction of the MR signal because an intra-voxel phase shift cannot be excluded; however, regarding the time course of a Gd-DTPA-induced signal change, this effect was considered to be not relevant. All enhanced images of the first and last contrast-enhanced series were processed by subtracting the corresponding precontrast scan images. In patients with breast implants due to reconstructive surgery, additional axial and sagittal T2-weighted fast spin-echo images were acquired to assess implant integrity. In women who had undergone ablative surgery of one or both breasts, MRI was acquired with the same imaging protocol as described above and additional fat-saturated T2-weighted fast spin-echo and contrast-enhanced T1-weighted spin-echo sequences to evaluate the thoracic wall and also the contralateral breast. In cases of bilateral ablation an MR imaging protocol using the torso coil with axial, sagittal T1-weighted spin-echo images, T2-weighted fast spin-echo, and contrastenhanced T1-weighted fat saturated spin-echo sequences were acquired.

\section{Image analysis}

All emission images were corrected for scatter and attenuation correction of the breast images (two fields of view) were done using segmented transmission data, i.e., predefined values for bone, tissue, and lung were assigned to the corresponding areas and smoothed with the same filters as the emission data to reduce statistical noise in the images of these short transmission scans $[14,15]$. The PET images were reconstructed with GEMS software release 4.1 using an iterative OSEM algorithm implemented on the PET camera for routine clinical use (2 iterative steps, 28 subsets, zoom of $1.0,128 \times 128$ image matrix, voxel size $4.39 \times 4.39 \times 4.25 \mathrm{~mm})$. For the whole-body scan filtered back projection was performed without attenuation correction.

The PET images were viewed in the three orthogonal imaging planes as well as by using cine mode on a digital viewing system (GE View, Dornstadt, Germany). Lesions were defined by increased uptake of FDG and compared with physiologic activity in the heart and brain. If a lesion was present within the two FOV over the breast, the same lesion was identified also in the wholebody scan to allow direct comparison with physiologic uptake in the brain. Intensity assessment of a lesion was thus performed using a scale between 1 (lung uptake) and 4 (brain uptake). This allowed semi-quantitative evaluation of FDG uptake into the lesions. Lesions with uptake comparable to the brain (uptake intensity 4 ) or more than normal liver uptake (uptake intensity 3 ) were considered to be malignant. Lesions with uptake intensity 1 (lung uptake) and 2 (normal liver uptake) were considered to be not ma- 
Table 2 Results of the imaging tests and the standard of reference. The reference standard and the definitive findings of PET and MRI scans are listed. Only lesions in the field of view of PET and MRI were used for statistical comparison. $M$ mammography;
$C T$ computed tomography; US ultrasound; $B P$ infiltration=infiltration of the brachial plexus; $L N$ lymph node; $T P$ true positive; $T N$ true negative; $F P$ false positive; $F N$ false negative; $D M$ distant metastases

\begin{tabular}{|c|c|c|c|c|c|c|c|}
\hline $\begin{array}{l}\text { Patient } \\
\text { no. }\end{array}$ & Standard & f reference & $\begin{array}{l}\text { Follow-up } \\
\text { after PET } \\
\text { and MRI } \\
\text { (months) }\end{array}$ & PET & MRI & Reason for MRI and PET & PET and MRI findings \\
\hline 1 & Negative & Follow-up (M, US) & 12 & FP & $\mathrm{TN}$ & $\begin{array}{l}\text { Ipsilateral }(10 \times 8 \mathrm{~mm}) \text { and } \\
\text { contralateral nodule on } \\
\text { mammography, palpable } \\
\text { axillary lymph node }\end{array}$ & $\begin{array}{l}\text { Normal ipsi- and contralateral } \\
\text { (fibroadenoma) findings and } \\
\text { normal lymph node on MRI, } \\
\text { suspected secondary cancer } \\
\text { on PET }\end{array}$ \\
\hline 3 & Positive & $\begin{array}{l}\text { Therapy } \\
\text { (bone metastases) }\end{array}$ & & TP, DM & $\mathrm{TP}$ & $\begin{array}{l}\text { Painful diffuse induration } \\
\text { of breast }\end{array}$ & $\begin{array}{l}\text { On MRI and PET recurrence } \\
\text { (Fig. 1) }\end{array}$ \\
\hline 4 & Negative & Follow-up (M) & 14 & $\mathrm{TN}$ & $\mathrm{TN}$ & $\begin{array}{l}\text { Nodule within the scar } \\
\text { (approximately } 6 \mathrm{~mm} \text { ) }\end{array}$ & $\begin{array}{l}\text { On MRI granuloma, on PET } \\
\text { uptake not increased }\end{array}$ \\
\hline 5 & Negative & Follow-up (M, US) & 14 & $\mathrm{TN}$ & $\mathrm{TN}$ & $\begin{array}{l}\text { Nodule on mammography, } \\
\text { solid on US }\end{array}$ & $\begin{array}{l}5 \times 7 \mathrm{~mm} \text { benign on MRI, } \\
\text { on PET uptake not increased }\end{array}$ \\
\hline 7 & Negative & Histology (surgery) & & $\mathrm{TN}$ & $\mathrm{TN}$ & $\begin{array}{l}\text { Painful induration with fistula } \\
\text { and palpable lymph node and } \\
\text { additional adjacent solid } \\
\text { lesion on US }(12 \times 7 \mathrm{~mm})\end{array}$ & $\begin{array}{l}\text { Fistula and lymph node } \\
(13 \mathrm{~mm} \text { ) on PET and MRI } \\
\text { visible, fistula } 3 \times 23 \mathrm{~mm} \\
\text { (pathology specimen), } \\
\text { no additional lesion }\end{array}$ \\
\hline 8 & Negative & Follow-up (M) & 12 & $\mathrm{TN}$ & $\mathrm{TN}$ & $\begin{array}{l}\text { Diffuse induration on } \\
\text { mammography fibrocystic } \\
\text { changes, palpable axillary } \\
\text { lymph nodes }\end{array}$ & $\begin{array}{l}\text { On MRI posttherapy changes } \\
\text { and two lymph nodes up to } \\
10 \mathrm{~mm} \text {, on PET uptake not } \\
\text { increased }\end{array}$ \\
\hline 9 & Negative & $\begin{array}{l}\text { Follow-up } \\
\text { (M, US, CT) }\end{array}$ & 16 & $\mathrm{FP}$ & $\mathrm{TN}$ & $\begin{array}{l}\text { Lesion on mammography } \\
\text { adjacent to the thoracic wall }\end{array}$ & $\begin{array}{l}\text { On MRI changes after radiation } \\
\text { treatment }(9 \times 12 \mathrm{~mm}) \text {, on PET } \\
\text { increased FDG uptake }\end{array}$ \\
\hline 10 & Positive & Follow-up (M, US) & 12 & $\mathrm{TP}$ & $\mathrm{FN}$ & $\begin{array}{l}\text { Diffuse induration in breast } \\
\text { and dense tissue on } \\
\text { mammography, palpable } \\
\text { nodules axillary and } \\
\text { supraclavicular } \\
(5 \times 7 \mathrm{~mm} \text { on US) }\end{array}$ & $\begin{array}{l}\text { Considered to be an } \\
\text { inflammation on MRI } \\
\text { (several centimeters), } \\
\text { suspected multifocal recurrence } \\
\text { on PET }\end{array}$ \\
\hline 12 & Negative & Follow-up (M) & 20 & $\mathrm{TN}$ & $\mathrm{TN}$ & $\begin{array}{l}10 \mathrm{~mm} \text { lesion on } \\
\text { mammography }\end{array}$ & $\begin{array}{l}\text { Fibroadenoma on MRI, on PET } \\
\text { uptake not increased }\end{array}$ \\
\hline 13 & Positive & Histology (surgery) & & $\mathrm{TP}$ & $\mathrm{FN}$ & $\begin{array}{l}\text { Palpable nodule within the } \\
\text { scar, solid lesion on US }\end{array}$ & $\begin{array}{l}\text { On MRI inflammation reaction } \\
\text { and fibrotic nodule } 9 \times 14 \mathrm{~mm} \text {, on } \\
\text { PET suspected local recurrence }\end{array}$ \\
\hline 14 & Negative & Histology (surgery) & & $\mathrm{FP}$ & $\mathrm{TN}$ & $\begin{array}{l}\text { On mammography dense } 1 \\
\text { esion } 14 \times 13 \mathrm{~mm} \text {, palpable }\end{array}$ & $\begin{array}{l}\text { On MRI posttherapeutic } \\
\text { changes (pathology specimen } \\
\text { with inflammation), on PET } \\
\text { suspected recurrence }\end{array}$ \\
\hline 15 & Positive & Cytology & & $\mathrm{TP}$ & $\mathrm{TP}$ & $\begin{array}{l}\text { On mammography two } \\
\text { nodules } 4 \times 5 \text { and } 9 \times 12 \mathrm{~mm}\end{array}$ & $\begin{array}{l}\text { On MRI and on PET suspected } \\
\text { local recurrence (on PET } 1 \\
\text { nodule detected) }\end{array}$ \\
\hline 16 & Positive & Histology (biopsy) & & $\mathrm{TP}$ & $\mathrm{TP}$ & $\begin{array}{l}\text { Palpable axillary lymph node } \\
\text { and scar, on US supected } \\
\text { lesion }\end{array}$ & $\begin{array}{l}\text { On MRI and PET suspected } \\
\text { axillary lymph node and } \\
\text { recurrence adjacent to a rib } \\
(14 \times 15 \mathrm{~mm})\end{array}$ \\
\hline
\end{tabular}


Table 2 (continued)

\begin{tabular}{lllll}
\hline $\begin{array}{l}\text { Patient Standard of reference } \\
\text { no. }\end{array}$ & $\begin{array}{l}\text { Follow-up } \\
\text { after PET } \\
\text { and MRI } \\
\text { (months) }\end{array}$ & & & \\
& & &
\end{tabular}

\begin{tabular}{|c|c|c|c|c|c|c|}
\hline 17 & Negative & Follow-up (M) & 12 & $\mathrm{TN}$ & $\mathrm{TN}$ & $\begin{array}{l}\text { Suspect nodule on } \\
\text { mammography and US } \\
(4 \times 5 \mathrm{~mm})\end{array}$ \\
\hline 18 & Positive & Histology (surgery) & & $\mathrm{TP}$ & $\mathrm{TP}$ & $\begin{array}{l}\text { On mammography "diffuse } \\
\text { transparency decrease" } \\
\text { (size N/A) }\end{array}$ \\
\hline 19 & Positive & Histology (biopsy) & & $\mathrm{TP}$ & $\mathrm{TP}$ & $\begin{array}{l}\text { On mammography nodule } \\
12 \times 11 \mathrm{~mm} \text { in the scar }\end{array}$ \\
\hline 20 & Positive & Histology (surgery) & & $\mathrm{TP}$ & $\mathrm{TP}$ & $\begin{array}{l}\text { Palpable nodule at thoracic } \\
\text { wall adjacent to the scar }\end{array}$ \\
\hline
\end{tabular}

21 Positive Cytology

TP TP Local pain at thoracic wall and clinical signs of brachial plexus infiltration, US dense lesion

$\begin{array}{lll}22 & \text { Positive } & \begin{array}{l}\text { Therapy } \\ \text { (bone metastases) }\end{array} \\ 23 & \text { Positive } & \begin{array}{l}\text { Therapy } \\ \text { (loco-regional LN } \\ \text { and soft tissues) } \\ \text { Cytology, therapy } \\ \text { (BP infiltration) }\end{array}\end{array}$

TP, DM TP Painful palpable induration adjacent to scar

On MRI posttherapeutic changes, on PET uptake not increased

On MRI two nodular lesions, on PET one lesion in the breast (pathology specimen two lesions 10 and $12 \mathrm{~mm}$ in the same breast)

On MRI and PET recurrence

On MRI lesion at thoracic wall adjacent to the scar and second lesion infraclavicular, on PET increased uptake in two lesions (pathology specimen 11 and $15 \mathrm{~mm}$ )

On MRI soft tissue invasion of tumor to the brachial plexus with nodules 8 and $13 \mathrm{~mm}$, on PET diffuse uptake

Lesion $13 \times 7 \mathrm{~mm}$ with infiltration of rib on MRI, on PET visible lesion and DM

TP TP Parasternal palpable nodule

Lesion on MRI $(20 \times 25 \mathrm{~mm})$ and PET

TP TP Nodules supraclavicular, infraclavicular and axillary with clinical signs of brachial plexus infiltration

25 Positive Cytology, therapy (loco-regional LN and soft tissues)

26 Negative Histology (surgery)

TP FN Palpable nodule in scar

FP FP Palpable axillary lymph nodes and on mammography star-like lesion

TN, DM TN Lesion on mammography $(15 \mathrm{~mm})$ on US dense

TP, DM TP On mammography fibrocystic disease and palpable axillary lymph node

29 Negative Follow-up (M)

TN

$\mathrm{TN}$

A palpable lesion (11 $\mathrm{mm}$ on mammography) and a second nodule $4 \times 5 \mathrm{~mm}$ on mammography

$30 \quad$ Negative Follow-up (M) 12

31 Negative Cytology, therapy (bone metastases)

32 Negative Histology (surgery)
TN TN Lesion on mammography $13 \mathrm{~mm}$

TN, DM TN

Fibrocystic disease on mammography with star-like lesion (size N/A)

TN TN On mammography two lesions $15 \times 10$ and $12 \times 16 \mathrm{~mm}$
On MRI several lymph nodes and lesion $12 \times 25 \mathrm{~mm}$ at brachial plexus, on PET all lesions visible

On MRI suspected granuloma $11 \times 9 \mathrm{~mm}$ and inflammation, on PET positive

On MRI suspect lesion in breast tissue $8 \times 14 \mathrm{~mm}$ and two lymph nodes (not malignant) $20 \mathrm{~mm}$ each, on PET increased uptake in all lesions

On MRI and on PET breast normal, only additional finding on PET (local lesion in cytology fibrotic tissue)

On MRI lesion $25 \times 17 \mathrm{~mm}$ and lymph node, on PET lesion visible and distant metastases On MRI fibroadenomas, on PET not visible

On MRI scar, on PET uptake not increased

Fibrocystic disease on MRI, no malignant lesion, on PET

normal breast and DM

On MRI no signs of malignancy, fibrocystic disease, on PET uptake not increased 

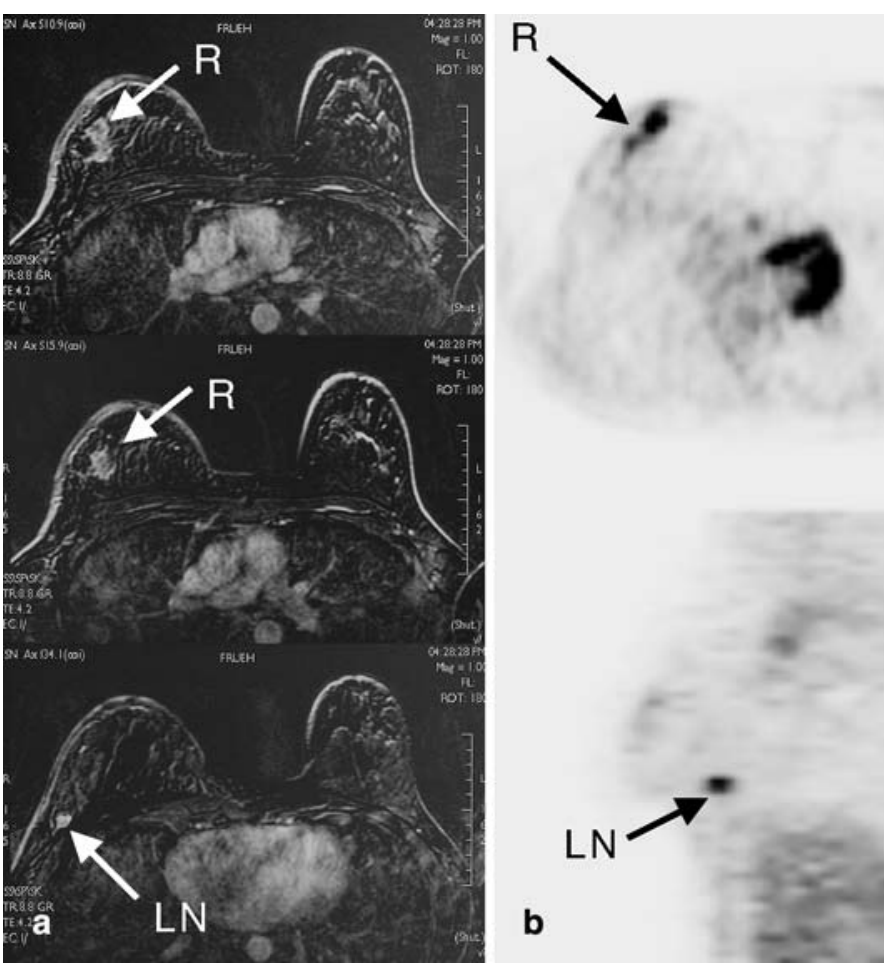

Fig. 1a, b Magnetic resonance imaging and fluoro-deoxy-glucose (FDG) positron emission tomography (PET) images of a 33-yearold woman (patient 3 ) with clinically suspected local recurrence. a Transverse early subtraction MR images (first contrast-enhanced image-precontrast image) illustrate early enhancement in the recurrent cancer $(R)$ and in a lymph node $(L N)$. b Sagittal and transverse PET images illustrating increased FDG uptake in the same lesions of recurrent cancer $(R)$. An additional lymph node metastasis in the retroclavicular region, outside the field of view (FOV) of MRI, is seen only in PET ( $\left.L N_{\text {outside }}\right)$

lignant, e.g., inflammation or posttherapeutic changes. Standardized uptake values were not routinely calculated for these patients, because iteratively reconstructed images were assessed and because the way of visual evaluation aimed at high sensitivity. The PET scans were read in consensus by two experienced nuclear medicine physicians (H.C.S. and G.W.G.) who were blinded for the results of the MR scans as well as other clinical and imaging information. After the decision had been made if a finding visible in the PET scan of the breast was benign or malignant, the PET scans were directly compared with the MR scans. This was done to identify if the lesion was located outside of the FOV of the MR scan, because the position of the patients' breast in the MRI could still be different from the position in PET.

In MRI, a semi-quantitative analysis of the signal intensity vs time curve was performed in lesions with early contrast enhancement as previously described [16]. A $>50 \%$ relative increase of signal intensity after contrast injection on early subtraction images was considered to be a sign for malignancy [16]. The MR images were documented on film, and image interpretation was performed in consensus by two experienced radiologists (A.H.K. and R.K-H.) blinded to clinical information and results of the PET scans.

\section{Statistical evaluation}

Lesions visible in the PET image and in the MR image were taken for statistical comparison. Lesions only visible in PET, i.e., in areas outside the FOV of the MR scan, were considered to be additional information of the PET scan and were not used for statistical comparison of both imaging methods. The values for sensitivity, specificity, positive and negative predictive value, and accuracy were determined. Furthermore, a McNemar test was performed to compare PET and MRI (significance level of $p=0.20$ for equal effects), and kappa was determined to quantify agreement of both methods.

\section{Results}

Cytology $(n=6)$, biopsy $(n=3)$, or histology after surgical intervention $(n=8)$ was available as a standard of reference in 17 of 32 patients (53\%; Table 2). The FNA was positive in 4 patients, negative in 2 patients, and not conclusive in 1 patient (patient 5; Table 2). In patient 10 FNA of a supraclavicular lymph node, but not of the breast itself, was done, showing inflammation reaction. This patient and patient 23 rejected further investigation of the local findings using FNA. In the other patients (ultrasound-guided) FNA of the suspected lesion was not done either because biopsy or surgical intervention was planned or because the patient preferred to undergo MRI prior to a more invasive procedure. In 9 women histology/cytology was positive for recurrence $(28 \%)$ and in 8 women negative (25\%; Table 2$)$. In the women with negative pathologic findings and no evidence of distant metastases (patients 2, 7, 11, 14, 26, 32) a routine follow-up examination after 1 year with 

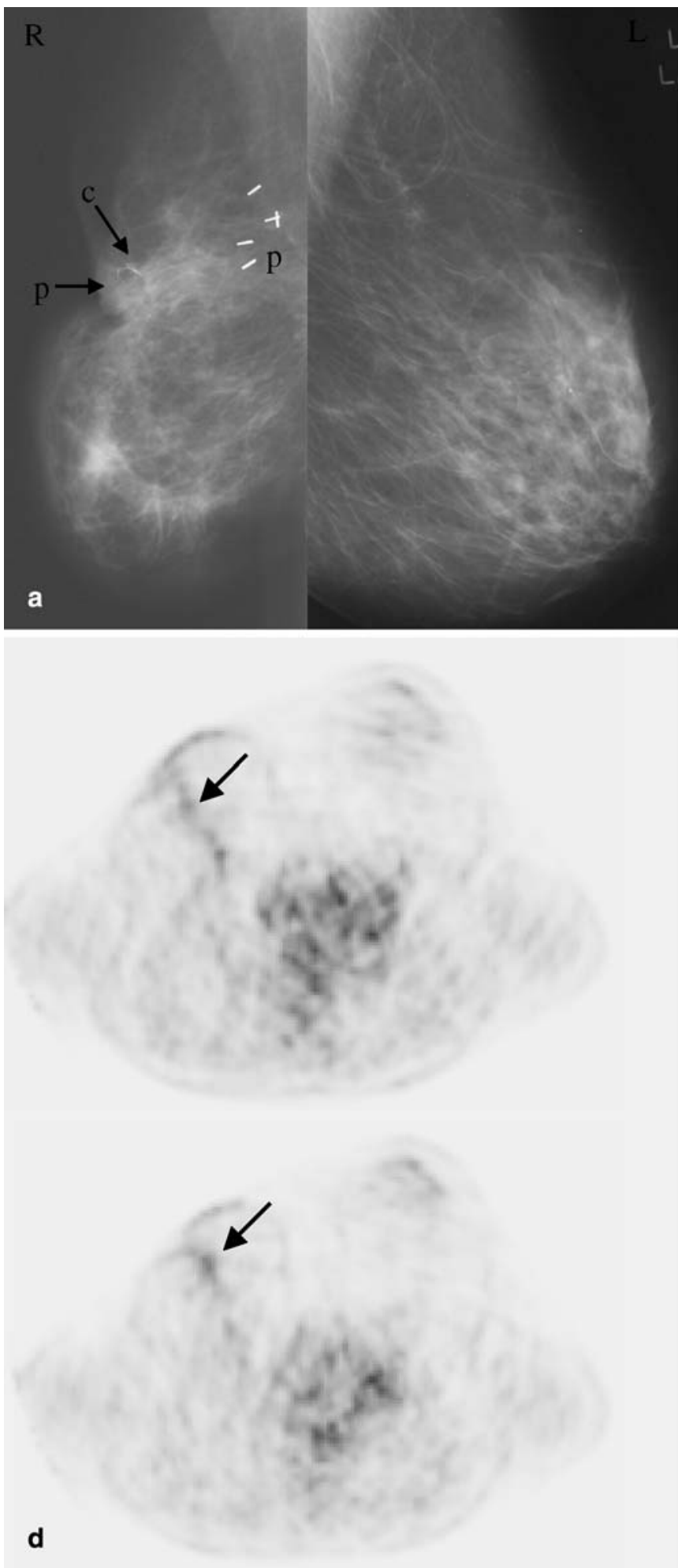

mammography with/without ultrasound was available without evidence of disease. In the 9 women with positive local findings in cytology/histology (patients 13, 15, 16, $18,19,20,21,24,25)$ a treatment of the local or regional recurrence was started.
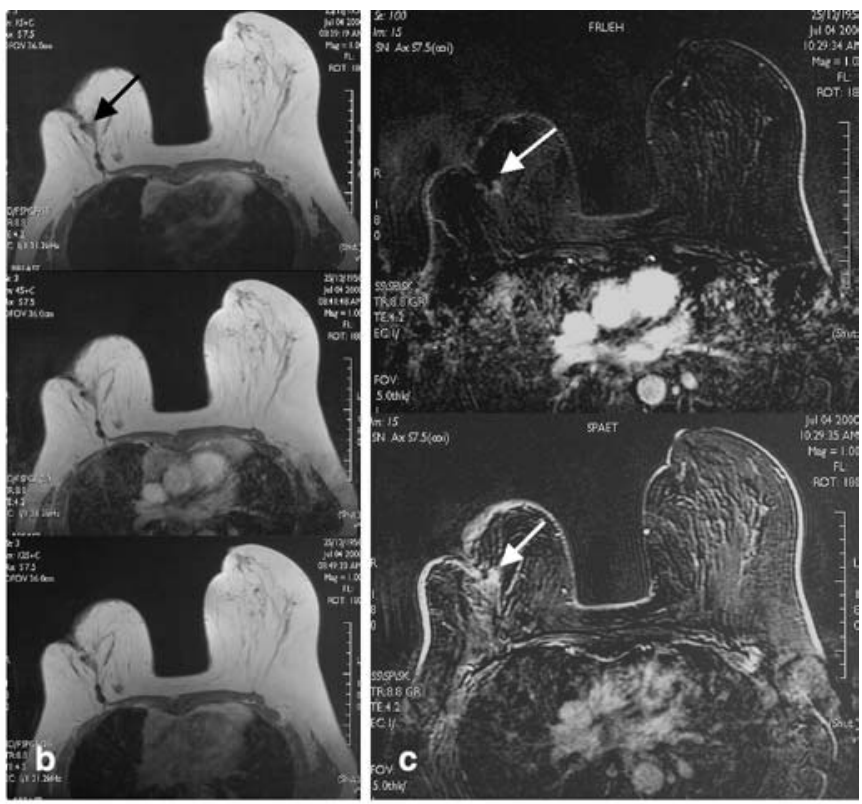

Fig. 2a-d Mammography, MRI, and FDG PET images of a 63-year-old woman (patient 2) with a suspected local recurrence in a routine mammography 45 months after the end of treatment. a Mammography of the right $(R)$ and left $(L)$ breast in a lateral view. There is postoperative deterioration of the soft tissues with metallic clips $(p)$. At the site of surgery the tissue is less radiolucent $(p)$. Egg-shell calcifications probably due to a cystic lesion are present $(c)$. b Transverse T1-weighted gradient-echo MRI images showing the identical slice over time with late enhancement of gadolinium contrast in a benign lesion of the right breast (arrow). c Transverse subtraction images of the same breast. The early (upper image; first contrast-enhanced image/precontrast image) and late (lower image; last contrast-enhanced image/precontrast image) images illustrate late enhancement of gadolinium contrast. This is suggestive of a benign lesion (arrows). d Two consecutive transverse PET images. There is only low FDG uptake within the scar, which is not suspicious for a local recurrence (arrows). Since the patient felt a hard nodule growing at this site, surgery was performed revealing fibrosis with calcifications

In 11 of 32 patients (patients $1,4,5,6,8,9,10,12$, $17,29,30$ ) a mean follow-up of 14 months (range 12-20 months) with an additional clinical examination and imaging served as the reference standard (Table 2). Mammography with/without ultrasound was performed if no lesion was suspected in MRI and PET. If a lesion was suspected in PET or MRI, one or more additional imaging examinations (mammography, ultrasound, CT of the chest) were performed together with clinical examination (Table 2). Only 1 of these 11 patients had a local recurrence (patient 10).

The 5 patients with distant metastases (patients 3, 22, $27,28,31$ ) underwent bone scintigraphy, CT or abdominal ultrasound and treatment with chemotherapy or bisphosphonates was started (Table 2). Two of these 5 patients (patients 27,31 ) receiving therapy for distant 
Table 3 Comparison of the imaging tests

\begin{tabular}{llr}
\hline & MRI & PET \\
\hline Sensitivity (\%) & 79 & 100 \\
Specificity (\%) & 94 & 72 \\
Positive predictive value (\%) & 92 & 74 \\
Negative predictive value (\%) & 85 & 100 \\
Accuracy (\%) & 88 & 84 \\
\hline
\end{tabular}

bone metastases had no evidence of loco-regional recurrence with MRI and PET (both considered true negative; Table 2). Examples of true-negative and true-positive MRI and PET findings are given in Figs. 1 and 2.

The PET was true positive in 14 women (44\%), true negative in 13 women (41\%), and false-positive in 5 women (16\%). There were no false-negative PET findings. The MRI was true positive in 11 women (34\%), true negative in 17 women $(53 \%)$, false negative in 3 women (9\%), and false positive in 1 woman. Findings of PET and MRI vs the standard of reference split for the different patient subgroups are listed in Table 2. The values for sensitivity, specificity, positive and negative predictive value, and accuracy are listed in Table 3. The PET had a higher sensitivity than MRI but a lower specificity. The results of the McNemar tests revealed no significant difference between the sensitivity of PET and MRI $(p=0.25)$ and between the specificity of PET and MRI $(p=0.25)$. In this study, both imaging methods MRI and PET had comparable accuracy $(p=1.0)$; however, the kappa coefficient between PET and MRI was $0.58 \pm 0.13$ indicating that both imaging tests could complement one another.

\section{Discussion}

Because mammography is less specific after breast surgery, the addition of sonography or MRI in women with breast cancer is useful for the evaluation of suspicious findings in the breasts and regional lymph nodes. While MRI is an established imaging method in suspected recurrence, only a few studies have been published showing a role of FDG PET in this situation. In a study by Bender et al. [5], PET detected significantly more often lymph node metastases in patients with suspected local recurrence than CT or MRI.

In the 19 patients in our study scanned for suspected loco-regional recurrence, 4 false-positive PET examinations were obtained, 1 of them showing contralateral uptake, which was thought to be a second tumor. In these patients who underwent mammography and clinical control of both breasts, the likelihood to detect a new contralateral cancer in a breast considered to be normal when using other imaging examinations is probably low, since increased FDG uptake can also be found in benign le- sions such as fibroadenoma [17]. Three false-positive PET findings were due to suspected lymph node or thoracic wall involvement. In 2 patients false-positive PET scans were confirmed to be negative by histology (patients 11 and 14). These patients had scar tissue with calcifications (patient 11) and non-specific inflammation (patient 14), respectively. The high rate of false-positive findings of PET is a well-known problem, since FDG is also taken up in inflammatory tissue [3, 18]. In this study no false-negative PET scans were found due to the highly sensitive way of visual image interpretation. In contrast, Moon et al. report a sensitivity and a specificity of FDG PET of 93 and $79 \%$ with a positive and negative predictive value of 82 and $92 \%$ for the detection of recurrence and metastases [19]. Using MRI we had 3 false-negative findings and 1 false-positive finding; hence, MRI had better specificity but lower sensitivity than FDG PET in this evaluation.

Whole-body PET identified additional metastases lying outside the FOV of the MR image in 5 patients (16\%), but only 3 also had a loco-regional lesion. In the other 2 patients a loco-regional problem was excluded. This finding was explained by the patient reporting pain at the anterior or lateral thoracic wall, which was in fact caused by vertebral or rib metastases not being visible in MRI with a limited FOV. In addition, we found that detection of supraclavicular lymph node metastases can be difficult, since in MR this region may be at the border or even outside of the FOV in tall women (Fig. 1). This region corresponds to the next level of possible lymph node involvement after resection of axillary lymph nodes. All women with distant metastases also had bone metastases, which were visible in the PET scans. It has been reported that osteolytic lesions show higher FDG uptake than osteoblastic lesions [20]. In the same patients we also found distant metastases in the liver or lung, which confirmed previous reports, underlining that whole-body FDG PET is a suitable restaging tool in breast cancer patients [3]. The capability of FDG PET to detect bone metastases at an early time point may be important, since appropriate therapy using bisphosphonates combined with cytotoxic or hormonal treatment can prevent both, the development of further bone metastases and pathological fractures [21].

Both PET and MRI were true positive in all 5 patients with local recurrence of the thoracic wall as verified using cytology/histology, CT, or bone scintigraphy. These patients had previously undergone mastectomy and, therefore, had FDG whole-body PET in supine position; however, the small number of patients in this study precludes to claim that PET and MRI are equally useful in these patients. In a study involving breast cancer patients with brachial plexopathy, Ahmad et al. [22] showed that FDG PET was able to identify 14 of 19 patients with pain and suspected recurrence, whereas CT was inconclusive or negative in 6 patients; therefore, further studies have to evaluate if FDG PET is useful in this patient group and if 
it can provide additional information compared with MRI, e.g., for the planning of a radiation treatment.

Forty-four percent of our patients received radiation treatment after surgery. Three patients (patients $1,8,15$ ) had their radiation treatment stopped less than 18 months prior to the acquisition of MRI and PET scans (Table 1). This is important, because up to 18 months after radiation treatment, interpretation of MRI can be difficult. Post-therapeutic inflammatory reactions can influence MR images leading to false-positive interpretation [23]. Also in PET, a radiation-induced inflammatory reaction may influence image interpretation. Based on observations in patients with head and neck cancer, it can be suggested that such an influence on PET imaging will not last for 18 months, but merely for several weeks [24]; however, in this study 1 true-negative and 1 truepositive PET and MR scan were found and the falsepositive PET scan in patient 1 was due to over-interpretation of a finding in the contralateral normal breast, which received no radiation treatment.

Eight patients were included in this study with an equivocal or suspicious finding in the contralateral breast. Fifty percent of these women had undergone previous chemotherapy (patients 25, 26, 29, 32). This treatment was stopped several months before the PET and MRI examination and the false-positive findings of PET and MRI in patient 26 and the false-negative MR scan in patient 25 cannot be explained by a treatment effect. In one of these women (patient 26) MRI and PET found a lesion suspicious for recurrence, which turned out to be inflammation tissue on histology.

In some patients we found it difficult to correctly identify the corresponding lesions in MRI and PET, since the patients' breasts did not always have exactly the same position during the two imaging sessions. For MRI, the breasts are placed in a dedicated surface coil which may compress the breast in a mediolateral way to avoid motion blurring [8]. Although PET imaging was performed in an identical position using an MRI breast coil holder with removed coil, we found that the breasts' position was different in some patients. This effect was more evident in women with large breasts, which seemed to be more compressed during MRI. We found also that co-registration of MRI and PET images of the breasts was not helpful.
There were several limitations to our study. The number of included patients is small and it might thus be to early to draw a definitive conclusion from our results. An additional limitation is that cytological/histological proof was only available in $53 \%$ of patients, whereas in the other patients a combination of additional imaging studies and clinical evaluation during a 12 - to 20-month follow-up served as the standard of reference.

Regarding the low value of kappa between PET and MRI, a combination of both methods could in principle improve patient management. In 4 false-positive PET scans MRI was clearly normal. In contrast, in two of three false-negative MRI scans a non-specific inflammation reaction was suspected in MRI, whereas PET was correctly positive. If in all patients both examinations would be performed routinely, and only findings would be accepted which are positive in both examinations, the specificity would increase at the cost of a lower sensitivity. Using PET as an initial imaging method and MRI as backup in cases of suspicious PET findings could be an interesting approach: in the case of a positive PET scan, a positive MRI could guide histological confirmation and a negative MRI could result in a wait-and-watch strategy. Using this approach, only patient 13 would be false negative and patient 26 false positive. Sensitivity and specificity of the combined imaging approach would then become 93 and $94 \%$ with an accuracy of $94 \%$.

\section{Conclusion}

In conclusion, these preliminary data suggest that PET and MRI are comparable in imaging patients with suspected breast cancer recurrence; however, these imaging methods should be reserved for selected cases with non-conclusive mammographic or sonographic findings. Although a combination of MRI and PET seems interesting from an academic point of view, such an approach would not be justified in a routine clinical setting due to the high cost.

Acknowledgements This study was partly supported by a grant from the Legat Frau Henriette Rossiez Treichler, Zurich, Switzerland. G.W.G. is an award winner of the Research and Education Fund of the European Association of Radiology. We thank M. Griff for help in preparing the manuscript and T. Berthold, C. Britt, L. Meier, and M. Farrell for their excellent technical assistance.

\section{References}

1. Adler LP, Crowe JP, al-Kaisi NK, Sunshine JL (1993) Evaluation of breast masses and axillary lymph nodes with [F-18] 2-deoxy-2-fluoroD-glucose PET. Radiology 187:743-750
2. Wahl RL (1998) Overview of the current status of PET in breast cancer imaging. Q J Nucl Med 42:1-7

3. Brix G, Henze M, Knopp MV, Lucht R, Doll J, Junkermann H, Hawighorst H, Haberkorn U (2001) Comparison of pharmacokinetic MRI and $[18 \mathrm{~F}]$ fluorodeoxyglucose PET in the diagnosis of breast cancer: initial experience. Eur Radiol 11:2058-2070
4. Eubank WB, Mankoff DA, Takasugi J, Vesselle H, Eary JF, Shanley TJ, Gralow JR, Charlop A, Ellis GK, Lindsley KL, Austin-Seymour MM, Funkhouser CP, Livingston RB (2001) 18Fluorodeoxyglucose positron emission tomography to detect mediastinal or internal mammary metastases in breast cancer. J Clin Oncol 19:3516-3523 
5. Bender H, Kirst J, Palmedo H, Schomburg A, Wagner U, Ruhlmann J, Biersack HJ (1997) Value of 18fluorodeoxyglucose positron emission tomography in the staging of recurrent breast carcinoma. Anticancer Res 17:1687-1692

6. Orel SG, Schnall MD (2001) MR imaging of the breast. Radiology 220:13-30

7. Mumtaz H, Davidson T, Hall-Craggs MA, Payley M, Walmsley K, Cowley G, Taylor I (1997) Comparison of magnetic resonance imaging and conventional triple assessment in locally recurrent breast cancer. Br J Surg 84:1147-1151

8. Friedrich M (1998) MRI of the breast: state of the art. Eur Radiol 8:707-725

9. Kraemer S, Schulz-Wendtland R, Hagedorn K, Bautz W, Lang N (1998) Magnetic resonance imaging in the diagnosis of local recurrences in breast cancer. Anticancer Res 18:2159-2162

10. Rieber A, Merkle E, Zeitler H, Gorich J, Kreienberg R, Brambs HJ, Tomczak R (1997) Value of MR mammography in the detection and exclusion of recurrent breast carcinoma. J Comput Assist Tomogr 21:780-784

11. Gilles R, Guinebretiere JM, Shapeero LG, Lesnik A, Contesso G, Sarrazin D, Masselot J, Vanel D (1993) Assessment of breast cancer recurrence with contrast-enhanced subtraction MR imaging: preliminary results in 26 patients. Radiology 188:473-478
12. Dao TH, Rahmouni A, Campana F, Laurent M, Asselain B, Fourquet A (1993) Tumor recurrence versus fibrosis in the irradiated breast: differentiation with dynamic gadoliniumenhanced MR imaging. Radiology 187:751-755

13. Hathaway PB, Mankoff DA, Maravilla KR, Austin-Seymour MM, Ellis GK, Gralow JR, Cortese AA, Hayes CE, Moe RE (1999) Value of combined FDG PET and MR imaging in the evaluation of suspected recurrent local-regional breast cancer: preliminary experience. Radiology 210:807-814

14. Bettinardi V, Pagani E, Gilardi MC, Landoni C, Riddell C, Rizzo G, Castiglioni I, Belluzzo D, Lucignani G, Schubert S, Fazio F (1999) An automatic classification technique for attenuation correction in positron emission tomography. Eur J Nucl Med 26:447-458

15. Hudson HM, Larkin RS (1994) Accelerated image-reconstruction using ordered subsets of projection data. IEEE Trans Med Imaging 13:601-609

16. Fischer U, Kopka L, Grabbe E (1999) Breast carcinoma: effect of preoperative contrast-enhanced MR imaging on the therapeutic approach. Radiology 213:881-888

17. Palmedo H, Bender H, Grunwald F, Mallmann P, Zamora P, Krebs D, Biersack HJ (1997) Comparison of fluorine-18 fluorodeoxyglucose positron emission tomography and technetium-99m methoxyisobutylisonitrile scintimammography in the detection of breast tumours. Eur J Nucl Med 24:1138-1145

18. Strauss LG, Conti PS (1991) The applications of PET in clinical oncology. J Nucl Med 32:623-648
19. Moon DH, Maddahi J, Silverman DH, Glaspy JA, Phelps ME, Hoh CK (1998) Accuracy of whole body fluorine18-FDG PET for the detection of recurrent or metastatic breast carcinoma. J Nucl Med 39:431-435

20. Cook GJ, Houston S, Rubens R, Maisey MN, Fogelman I (1998) Detection of bone metastases in breast cancer by FDG PET: differing metabolic activity in osteoblastic and osteolytic lesions. J Clin Oncol 16:3375-3379

21. Hillner BE, Ingle JN, Berenson JR, Janjan NA, Albain KS, Lipton A, Yee G, Biermann JS, Chlebowski RT, Pfister DG (2000) American Society of Clinical Oncology guideline on the role of bisphosphonates in breast cancer. American Society of Clinical Oncology Bisphosphonates Expert Panel. J Clin Oncol 18:1378-1391

22. Ahmad A, Barrington S, Maisey M, Rubens RD (1999) Use of positron emission tomography in evaluation of brachial plexopathy in breast cancer patients. Br J Cancer 79:478-482

23. Heywang-Kobrunner SH, Schlegel A, Beck R, Wendt T, Kellner W, Lommatzsch B, Untch M, Nathrath WB (1993) Contrast-enhanced MRI of the breast after limited surgery and radiation therapy. J Comput Assist Tomogr 17:891-900

24. Keyes JW, Watson NE, Williams DW, Greven KM, McGuirt WF (1997) FDG PET in head and neck cancer. Am J Roentgenol 169:1663-1669 